\title{
Eruptive syringomas - a diagnostic challenge: Resistant to oral isotretinoin
}

\section{Shashank Bhargava}

\author{
R. D. Gardi Medical College, Ujjain, India
}

Corresponding author: Dr. Shashank Bhargava, E-mail: shashank2811@gmial.com

\begin{abstract}
A syringoma is an appendageal neoplasm which is benign and commonly affects adolescent females. A 23-year-old female presented with multiple asymptomatic, skin-colored lesions of 4 months duration which were progressive in nature. Lesions started from face which later spread to neck and chest. Cutaneous examination revealed multiple skin-colored papules over the face (infra-orbital and above the upper lip) neck and chest with few discrete papules over both the upper limbs and abdomen. Histopathological examination revealed normal epidermis with benign adnexal neoplasm composed of small-island and duct-like structure embedded in collagen in the upper dermis. Small ducts were lined with a double row of flattened epithelial cells which form a comma-like projection (tails) and gave them the appearance of tadpole. Patient was started on oral isotretinoin $20 \mathrm{mg}$ for 4 months but she did not show any improvement. Finally, she underwent ablation using $\mathrm{CO}_{2}$ laser.
\end{abstract}

Key words: Eruptive; Syringoma; Isotretinoin; $\mathrm{CO}_{2}$ laser

\section{INTRODUCTION}

The word syringoma is derived from Greek language syrinx meaning a tube. A syringoma is an appendageal neoplasm which is benign and commonly affects adolescent females. Clinically, they appear as multiple small papules which are skin colored or slightly brown in color. They are symmetrically distributed and usually involve periorbital area and neck. The other sites like axillae, abdomen and extremities are also involved. Four major variants as proposed by Friedman and Butler [1] are localized, familial, generalized including eruptive and multiple and associated with Down syndrome [2-4].

\section{CASE REPORT}

A 23-year-old female presented with multiple asymptomatic, skin-colored lesions of 4 months duration which were progressive in nature. Lesions started from face which later spread to neck and chest up to the suprasternal area. There was no similar history in any of the family members. No significant medical or surgical history was present. She refused any use of medication prior to development of lesion. Cutaneous examination revealed multiple skin-colored papules over the face (infra-orbital and above the upper lip) neck and chest bilaterally (Figs. 1 and 2) of varying size from 1 to $4 \mathrm{~mm}$. There were few discrete papules over both the upper limbs and abdomen. Palms and soles, mucous membrane, nails and scalp were spared. They had smooth surface and were nonindurated. Systemic examination was insignificant. Biopsy sample was taken from one of the papules over the chest keeping syringoma, verruca plana, acrokeratosis verruciformis of Hopf and sebaceous hyperplasia as clinical differentials. Histopathological examination revealed normal epidermis with benign adnexal neoplasm composed of small-island and duct-like structure embedded in collagen in the upper dermis. The tumour cells were monomorphic and had round-to-vesicular nuclei with eosinophilic cytoplasm. Small ducts were lined with a double row of flattened epithelial cells which form a comma-like projection (tails) and gave them the appearance of tadpole were

\footnotetext{
How to cite this article: Bhargava S. Eruptive syringomas - a diagnostic challenge: Resistant to oral isotretinoin. Our Dermatol Online. 2018;9(4):428-430.

Submission: 16.01.2018; Acceptance: 09.05.2018

DOI:10.7241/ourd.20184.18
} 
seen (Fig. 3). Findings were consistent with the clinical diagnosis of syringoma. Patient was started on oral isotretinoin $20 \mathrm{mg}$ for 4 months but she did not show

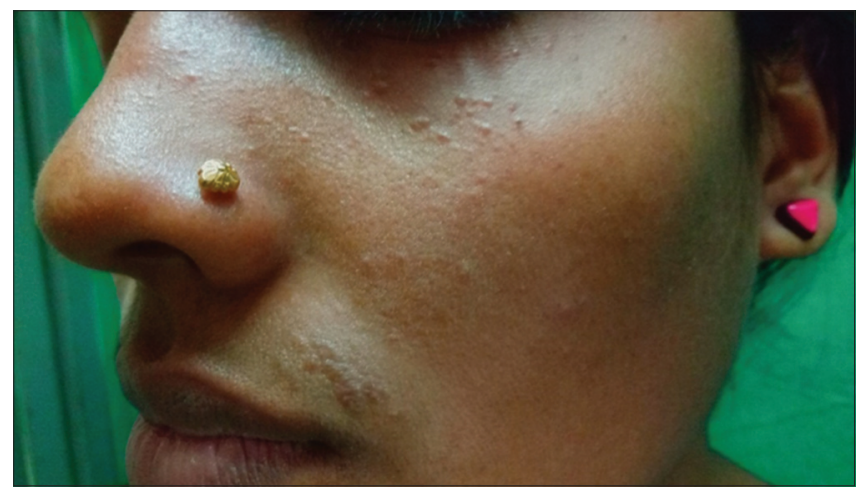

Figure 1: Multiple skin colored papules over the lower eyelid and above the upper lip.

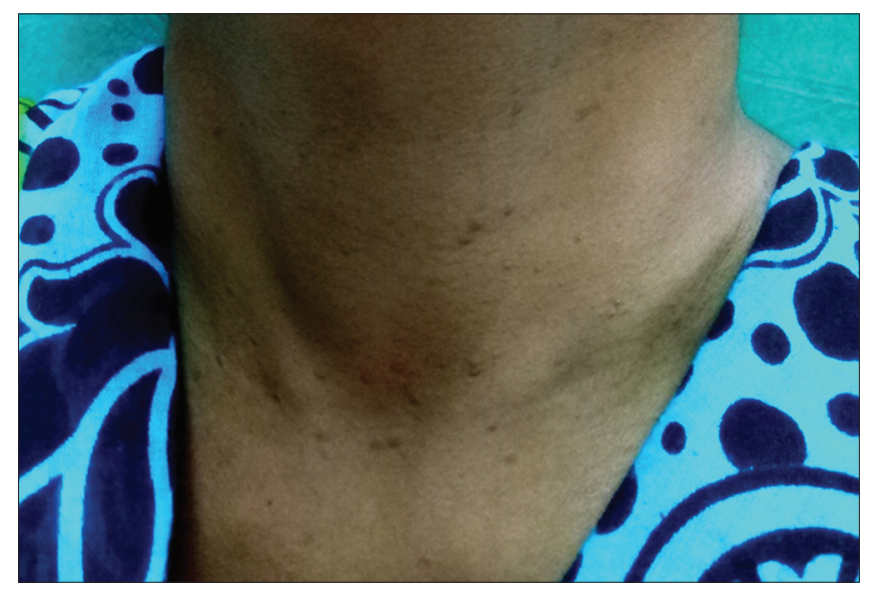

Figure 2: Multiple hyperpigmented papules over the anterior part of neck extending till the supra-sternal area.

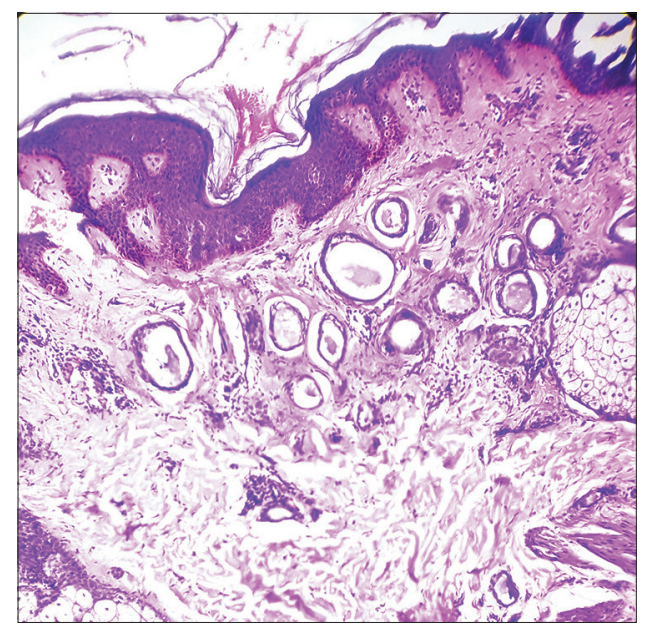

Figure 3: Histopathology shows normal epidermis with benign adnexal neoplasm composed of small-island and duct-like structure embedded in collagen in the upper dermis. Small ducts are lined with a double row of flattened epithelial cells which form a comma-like projection (tails), giving appearance of 'tadpole'. (H \& E stain, 10x). any improvement. Finally, she underwent excision using $\mathrm{CO}_{2}$ laser.

Prior to the study, patient gave written consent to the examination and biopsy after having been informed about the procedure.

\section{DISCUSSION}

Syringoma is a common benigh adnexal tumor composed of small solid and ductal elements embedded in a stroma and by convention located in the upper to mid dermis. They are commonly observed in adolescent females as multiple skin to brown colored lesions on the lower eyelids and cheeks. A rare type of syringoma is the eruptive or disseminated one. It was first described in 1887 by Jacquet and Darier. Eruptive syringomas are characteristically seen as rapid development of hundreds of small (1-5 mm), ill to well defined, smooth surfaced, skin-colored, pink, yellowish, or brownish papules typically involving the face, neck, trunk, genitalia and extremities. They have both follicular and non-follicular involvement. The pathogenesis of eruptive syringoma is still unknown. Garrido-Ruiz et al support that eruptive syringomas are due to hyperplastic response of the eccrine duct to an inflammatory reaction like contact dermatitis, shaving, laser hair removal, alopecia areata, radiation dermatitis etc. [5]. Chandler and Bosenberg presented evidence that eruptive syringomas are a resultant of autoimmune damage to acrosyringium and proposed the term autoimmune acrosyringitis with ductal cysts [6]. Recently, a systematic review by Williams and Shinkai, it was proposed that the strongest association of syringomas was with Down's syndrome (22.2\%), diabetes mellitus (2.1\%), Ehlers-Danlos syndrome, Marfan's syndrome and hyperthyroidism. Cases of syringomas in association with milia cysts and atrophoderma vermiculata are referred to as the Nicolau-Balus syndrome [7]. Eruptive syringomas often create significant cosmetic concern for patients. The treatment options include excision, dermabrasion, cryotherapy, chemical peels especially trichloroacetic acid, topical atropine, lasers like carbon dioxide laser and pulsed dye laser. All the modalities are associated with post-treatment adverse events such as scarring and dyspigmentation [8]. Oral isotretinoin was reported as a successful treatment in two cases with cumulative doses of 9 and $1 \mathrm{lg}$ isotretinoin over a 5-6-month period with significant improvement in reduction of number and size of syringomas [9]. There have been few reports with no improvement with Isotretinoin [10]. 


\section{CONCLUSION}

Eruptive syringomas are very rare and require early diagnosis with prompt treatment as they are of cosmetic concern for patients to face the society.

\section{Consent}

The examination of the patient was conducted according to the Declaration of Helsinki principles.

\section{REFERENCES}

1. Friedman SJ, Butler DF. Syringoma presenting as milia. J Am Acad Dermatol. 1987;16:310-4.

2. Williams K, Shinkai K. Evaluation and management of the patient with multiple syringomas: a systematic review of the literature. J Am Acad Dermatol. 2016;74:1234-40.

3. Soler-Carrillo J, Estrach T, Mascaró JM. Eruptive syringoma: 27 new cases and review of the literature. J Eur Acad Dermatol Venereol. 2001;15:242-6.

4. Guitart J, Rosenbaum MM, Requena L. Eruptive syringoma: a misnomer for a reactive eccrine gland ductal proliferation? J Cutan Pathol. 2003;30:202-5.

5. Garrido-Ruiz MC, Enguita AB, Navas R, Polo I, Rodríguez Peralto JL. Eruptive syringoma developed over a waxing skin area. Am J Dermatopathol. 2008;30:377-80.

6. Chandler WM, Bosenberg MW. Autoimmune acrosyringitis with ductal cysts: reclassification of case of eruptive syringoma.J Cutan Pathol. 2009;36:1312-5.

7. Williams K, Shinkai K. Evaluation and management of the patient with multiple syringomas: a systematic review of the literature. J Am Acad Dermatol. 2016;74:1234-40.

8. Seirafi HH, Akhyani M, Naraghi ZS, Mansoori P, Dehkordi HS, Taheri A, et al. Eruptive syringomas. Dermatol Online J. 2005;11:13.

9. Mainitz M, Schmidt JB, Gebhart W. Response of multiple syringomas to isotretinoin. Acta Derm Venereol. 1986;66:51-5.

10. Resende C, Araujo C, Santos R, Pereira T, Brito C. Late-onset of eruptive syringomas: a diagnostic challenge. An Bras Dermatol. 2015;90:239-41.

Copyright by Shashank Bhargava. This is an open-access article distributed under the terms of the Creative Commons Attribution License, which permits unrestricted use, distribution, and reproduction in any

medium, provided the original author and source are credited.

Source of Support: Nil, Conflict of Interest: None declared. 